\title{
Why young consumers are not open to mobile marketing communication
}

\author{
Ian Grant \\ University of Strathclyde \\ Stephanie O'Donohoe \\ The University of Edinburgh
}

\begin{abstract}
This paper explores young people's motivations for using mobile phones. Older adolescents' everyday use of traditional and new forms of mediated communication were explored in the context of their everyday lives, with data generated from self-completion questionnaires, diaries and mini focus groups. The findings confirm the universal appeal of mobile phones to a youth audience. Social and entertainment-related motivations dominated, while information and commercially orientated contact were less appealing. While marketers are excited by the reach and possibilities for personalisation offered by mobile phones, young people associated commercial appropriation of this medium with irritation, intrusion and mistrust. In other words, while marketers celebrated mobile phones as a 'brand in the hand' of youth markets, young people themselves valued their mobiles as a 'friend in the hand'. This suggests that the way forward for mobile marketing communications is not seeking or pretending to be young consumers' friend, but rather offering content that helps them maintain or develop the personal friendships that matter to them.
\end{abstract}

\section{Introduction}

According to Pedrozo and Wilska (2004, p. 4), the adoption of mobile phones has been 'one of the most conspicuous social changes to happen over the last ten years'. Certainly, use of mobile phones has risen rapidly with improvements in handheld technology and reception, and with convergence of video, data and audio services within the one device. Indeed, in March 2006, industry analyst Informa reported that the average mobile penetration rate for western Europe had reached 103\% (Ahonen 2006). 
While Steinbock (2005) argues that market saturation has shifted marketers' attention from penetration rates to usage levels, markets are still growing thanks to multiple subscriptions. In Italy, for example, where Informa reported a penetration rate of $124.6 \%$, the market still increased by $12 \%$ in 2005 (Ahonen 2006).

Mobile devices are particularly appealing to marketers due to their potential for targeting, interacting with and establishing relationships with consumers. Indeed, Rohm and Sultan (2005) argue that handheld mobile devices allow marketers to deliver personalised, context- and location-specific messages to individual members of a target market. They note that global brands such as McDonald's, Coca-Cola, MTV and Nike are all advanced in their development of mobile marketing communications (MMC) initiatives. They also report on adidas International's use of MMC to reach the global youth market and obtain impact, involvement and consumer activation.

The targeting of youth markets through MMC is hardly surprising, since young people seem to be particularly receptive to this 'brand in the hand' (Bigelow 2002; Rohm \& Sultan 2005). Indeed, a survey of 1058 British 11-21-year-olds in 2004 found that $95 \%$ had access to a mobile phone, and 77\% 'could not bear to be without' it (Haste 2005). Mobile phones are essential to many youth lifestyles: not only do they serve as fashion statements but they also help their owners connect with and synchronise peer networks (Tully 2002; Berelowitz 2005), and participate in television or radio programmes (Bughin 2004). Mobile phones also serve as personal, portable multi-media devices: Haste (2005), for example, found that almost one-third of British 11-21-year-olds used their mobile phones to surf the internet at least once a day, while a quarter used them to take photographs every day. As mobile phones improve their capacity for storing downloaded music and video content, they are likely to become even more indispensable to young consumers.

This suggests that young people's use of mobile phones, and the factors driving this, is a topic worthy of marketers' attention. Research into consumer motivations for using mobile phones remains in its infancy, however; as Agnelli et al. (2004, p. 1) note, '[t]he consequences of this worldwide invasion have still to be properly mapped and understood.' In this paper, we review prior research on mobile phone usage, before reporting on a multi-method study that examined older adolescents' motivations for, 
and experiences of, using mobile phones, and their views on mobile marketing communications.

\section{Prior research on mobile phone use}

There are still relatively few published studies of mobile phone use. Several have focused on differences in adoption patterns between young people and other users. For example, Mante-Meyer and Haddon (2001) found that adoption rates fell away among those over 20. Studies focusing on the social context of adoption have been conducted primarily among Scandinavian adolescent audiences, perhaps reflecting the quick acceptance of mobile phones in that part of the world. Studies by Oksman and Raitiainen (2001) in Finland, and Skog (2002) in Norway, suggested that teenagers are not homogeneous audiences for mobile phones: their attitudes and usage patterns varied widely according to factors such as social background, gender, urban/rural lifestyles, and technological literacy. These studies also highlighted how mobile phones have become integrated into young people's everyday lives.

An alternative approach has been to treat mobile phones as a medium and identify the particular uses and gratifications they offer consumers. Uses and gratifications theory has been hailed as 'one of the most influential theories in the field of communications research' (Lin 1996, p. 574). It assumes that media audiences are active, seeking goal-directed gratification, that the choice of media lies with the individual, and that media compete with other sources for consequent satisfaction (Katz et al. 1973). The tradition has, however, attracted criticism in the past for theoretical and methodological flaws (O'Donohoe 1994). In particular, it has been associated with positivistic research approaches and self-completion questionnaire methods. Despite these criticisms, the emergence of new and interactive forms of media has revitalised this research tradition, since there is a good fit between its assumptions and the interactive, goal-orientated way in which new media such as the internet are used (Eighmey \& McCord 1998; Ruggiero 2000).

Several studies have adopted a traditional uses and gratifications approach in examining mobile phone use. Leung and Wei (2000), for example, identified seven different gratifications: 'fashion/status', 'affection/ sociability', 'relaxation', 'mobility', 'immediate access', 'instrumentality' 
and 'reassurance'. A study of texting in Germany (Höflich \& Rössler 2001) identified broadly similar gratifications. Both studies focused on general adult samples, however, raising questions about the applicability of their findings to younger consumers.

Several other studies, from a wide range of disciplines, offer some insights into the appeal of mobile phones to this market. They point to the symbolic value of these products, with ownership of particular mobile phones communicating fashionability or individuality (Taylor \& Harper 2001; Ling 2004). Using mobile phones may also help young people gain and maintain peer group acceptance (Oksman \& Turtiainen 2004; Haste 2005). The 'linking value' of goods and services has been emphasised by Cova (1994, p. 307), who suggests that 'to satisfy their desire for communities, postmodern individuals seek products and services less for their use value than for their linking value'. Applying this perspective to mobile phones, Jones (2002) argues that young people's mobile phone use can be seen as 'neo-tribalism' in action, as it symbolises shared values and interests. Similarly, Taylor and Harper (2001) found that, for 11-18-year-olds, particular words and symbols became part of the tacit knowledge 'owned' by certain social networks, and were used when texting to signify group membership and distinguish others as 'outsiders'. Furthermore, the potential to contact others in an emergency offers a sense of security and reassurance to young people, not to mention their parents (Haste 2005).

Several researchers have started to explore issues of mobile phone consumption, identity and general societal impact. Their work often highlights problematic as well as positive aspects of mobile use. Peer-to-peer mobile communications may include acts of malice and intimidation (Haste 2005; NCH 2005), for example, and signs of annoyance with commercial communications targeting young people are emerging (Monk et al. 2004). More abstract, but no less significant, concerns have been raised by others. For example, Agnelli (in Vanderbeeken 2004, p. 2; see also Agnelli et al. 2004) argues that mobile phones have led to the overlapping of digital and physical space, so that physical presence no longer implies attentiveness or availability, and distinctions between public and private space are eroded. Dholakia and Zwick (2003) review debates in the technological literature on whether mobile technology offers people greater freedom and creativity or enslaves them through the greater potential for surveillance and monitoring by the powerful. They suggest that 'mobile communications 
means accessibility, and more importantly, the obligation to be accessible' (p. 10), and also the erosion of boundaries between spaces for work, consumption and recreation.

There is, however, relatively little research evidence concerning the extent to which more problematic aspects of mobile phone use match young people's everyday experiences. In particular, there is also little evidence on how - or whether - mobile marketing communications (MMC) fit into young people's everyday mobile phone use. Literature to date has either focused exclusively on relationships between mobile marketing and consumers (Mort \& Drennan 2004) or ignored its presence altogether. This study sets out, then, to locate young consumers' experiences of MMC within the context of overall mobile use.

\section{Research objectives, approach and method}

The findings reported below are drawn from a wider study examining the relationships between young people, new media and commercial practices. The research objectives related to this paper were to:

- ascertain levels of mobile access and use among older adolescents

- identify their uses and gratifications for mobile phones, compared with other forms of new media such as the internet

- understand older adolescents' experiences of and attitudes towards mobile marketing communications.

To achieve these objectives, the study used a multi-method approach, working within an interpretive paradigm. Ruggiero (2000, p. 25) concluded that 'to truly understand new media technologies, critical scholars should learn to embrace multiple levels of analysis'. In this study, quantitative survey methods provided a backdrop of descriptive information concerning young people's media uses and gratifications, while qualitative methods offered richer, deeper understanding of these.

The sample consisted of 13-17-year-olds, in the final three years of secondary school education in the UK. Young people were the focus of this study because they have been depicted as the embodiment of the digital world (Katz 1996), ideally suited to the challenges posed by new forms of media (Buckingham 2000). The viewpoints of older adolescents are particularly important: on the cusp of adulthood, they have a sophisticated 
understanding of marketing practices (Ritson \& Elliott 1999), experiment with new ideas and concepts (Arnett 2000), and influence both older and younger groups. As indicated earlier, young people are an attractive target for many marketers. Their interest in - and heavy use of - mobile phones makes them particularly important to marketers working with mobile brands or attempting mobile marketing communications.

Interpretive research methods stress the need for a contextualised and local understanding of the phenomenon in question. Access to adolescents was gained through three secondary schools: one urban fee-paying, one suburban state and another rural state school. These three schools offered diversity in geographic location, school type and affluence. The latter was measured using McLoone's (1997) neighbourhood deprivation, or DEPCAT, scores, which ranged from 1 (the least deprived) to 5 (the most deprived). Not surprisingly, the urban fee-paying school scored 1. The state suburban school had a score of 4 , while the rural state school scored 3. The fieldwork was completed in 2004 and involved a total of 175 participants on the east coast of Scotland.

A self-completion questionnaire was filled in by participants, covering media access and use, attitudes towards marketing, media and ICT, and the uses and gratifications of six major media types including mobile phones. Questionnaires were supplemented with a seven-day media dairy, modelled on the diary used in BMRB's TGI study (2001). The subsequent qualitative research was guided by the philosophical tradition of phenomenology ('Thompson et al. 1989), since it aimed to explore adolescents' 'lived in' experiences of using mobile phones. Mini group discussions took place with three teenagers who had self-identified as forming a 'natural friendship triad' (Mitchell 1997). This was intended to enhance group interaction and reflect the social context of media use, while also retaining access to individual accounts of experience (Robson 1993). In total, 15 groups were selected across the three school types, and each group met three times with the first author. In the first 'ice-breaker' session, participants were each given a disposable camera and asked to make a photographic record of 'a week in your life', both within and beyond the confines of their homes. This was intended to offer some insight into the cultural contexts and lifestyles in which they experienced and used media. When the photographs had been developed (and edited, if they wished), the groups reconvened to sort the images into groups and use these as a 
stimulus to discuss their lifestyles. The final meeting involved more focused discussion of their experiences of new media and marketing communications. The qualitative data were coded with the aid of NVivo and analysed according to phenomenological principles.

\section{Main findings}

The discussion below first considers issues of mobile phone access and use, before focusing on motivations for mobile use and issues concerning commercial communications.

\section{Media access and use}

As illustrated in Figure 1, it was evident that mobile phones were one of the most important, if not the most important media device for these young people. Over $90 \%$ claimed to have access to their own mobile phone, despite one-third of the sample coming from an area with a relatively high DEPCAT score. Girls were slightly more likely to own a mobile than boys ( $94 \%$ of girls and $88 \%$ of boys claimed ownership). These figures, and the gender balance of ownership, are consistent with other recent studies of young people in Britain (Madell \& Muncer 2004; Haste 2005).

Perhaps of greater relevance than the absolute figures was the comparison with other media choices available to the young people in this study. Mobile phones were more popular than MP3 players, computers, gaming machines and digital cameras. Mobile phones were used by $80 \%$ of the sample on a daily basis, second only to television (96\%). Not surprisingly, this figure was highest among those from the urban fee-paying school and lowest among those from the less affluent suburban state school. Since this study was conducted, convergence between digital devices has increased dramatically. Mobile phones, however, continue to be the focal point of many current IC'T-based brand campaigns.

Supplementary media diaries showed mobile communication taking place every hour of the day, from first thing in the morning to last thing at night - at home, at school, and often in transit (see Figure 2). Most hours recorded were after school, with consistent levels between the hours of 1600 and 2000 on weekdays. The research also highlighted the popularity of texting. This was the third most common media-related activity, after 
Figure 1: Media access - household and personal bedroom

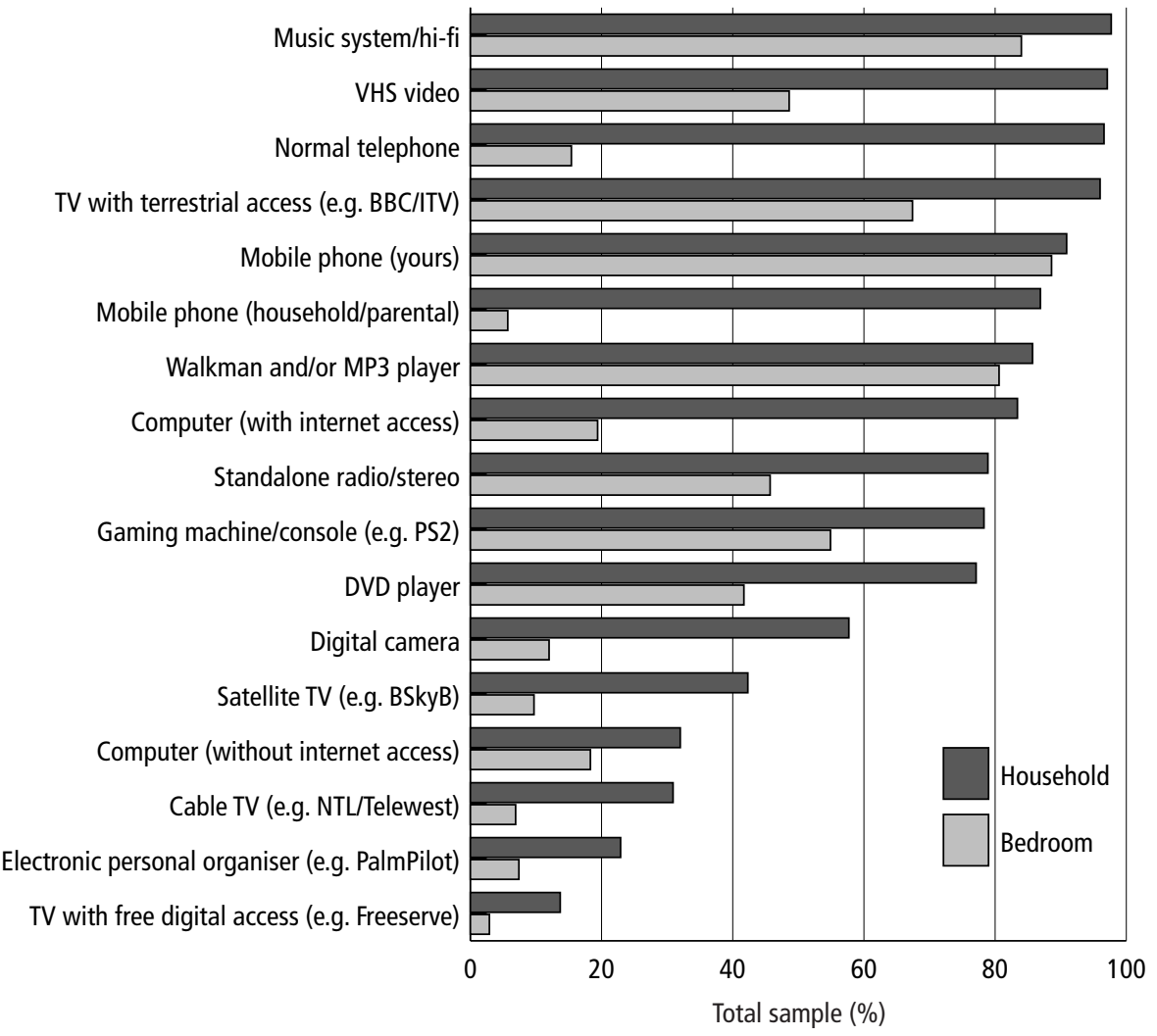

Sample size: 175 participants

watching TV and listening to music; it was twice as popular as any other form of telephonic communication, with an average of 10.09 minutes per day per person, compared with 3.02 minutes of talk on mobile phones and 6.79 on landlines. Cost factors are likely to have influenced the balance of these activities, since texts were considerably cheaper than mobile calls, and parents may have paid for calls on the landline. Since this study was conducted, mobile costs have dropped considerably, and network contracts are based on inclusive minutes, with many different bundles of texts and calls on offer. Nonetheless, Haste (2005) indicates that the appeal of texting was not simply economic: compared with mobile and landline talk, it was the preferred medium for seven of twelve communication activities. 
Figure 2: Hourly patterns of telephonic-based media

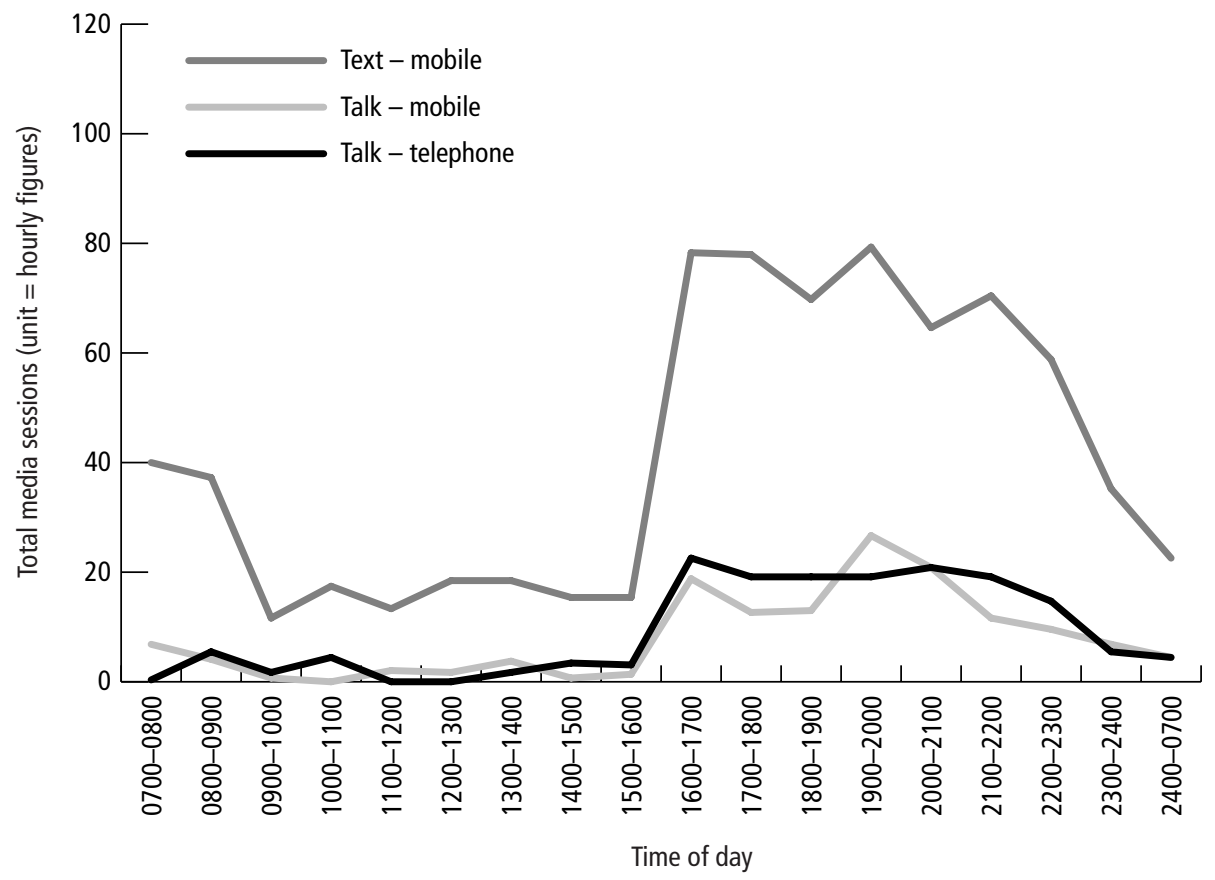

Sample size: 119 participants, 294 daily diaries (7-day diaries)

She found that $54 \%$ of $11-21$-year-olds texted friends at least five times a day, while $16 \%$ called their friends on their mobile at least five times a day. Similarly, Madell and Muncer (2004) found 11-16-year-olds texted more frequently than they called, with $8 \%$ of their sample texting more than 16 times a day.

In this study, the number of minutes recorded for texting was sometimes as low as three to five minutes per hour, but there were also examples of almost continuous texting through each hour of the waking day. Figure 2 shows that, during weekdays, a surprising amount of texting was conducted first thing in the morning - young people seemed eager to communicate with friends almost upon waking. Texting continued on the way to school, outside and undoubtedly inside school hours, although the figures for weekend use showed a small dip between 1400 and 1700. Like watching television, texting continued at a high level throughout the evening until after 2100; one male participant from the rural state school 
referred to 'burning something like $£ 5$ a night' on texting, and nightly sessions of constant texting back and forth were reported in several diaries.

Taken together, Figures 1 and 2 indicate that mobile phones were an essential media device for young people, woven into the fabric of their daily lives. Indeed, although their mobile phones were discussed with great enthusiasm, they scarcely featured in the photographs of their week; participants stated that mobiles were just a taken-for-granted part of their everyday lives. The only exception to this was the new generation of camera or video phones, which were still quite novel at the time of the fieldwork.

\section{Motivations for using mobile phones}

The young people's motivations for using a range of media were examined through 24 'uses and gratifications' statements, across six different media choices (mobile phones, internet, television, radio, magazines, and cinema). Derived from earlier new media studies, the statements were standardised for comparison across media. Exploratory factor analysis was conducted using principal component analysis. From the 175 participants, 167 sets of responses were completed sufficiently for analysis. A 1:7 ratio of variables to cases was deemed sufficient to proceed (Hair et al. 1998). As presented in Table 1, an optimal five-factor solution, accounting for $61.678 \%$ of the variance, was arrived at. These factors were labelled 'convenient entertainment', 'social stimulation', 'experiential learning', 'escapism' and 'purchase information and advice'. The following section will discuss each factor, with more detailed discussion drawing on the qualitative findings.

\section{Factor 1: Convenient entertainment}

The loading of the statement 'because it entertains me' dominated this first factor, although it should be noted that the mean scores for this statement were lower for mobile phones than for most other media included in the survey. What mobiles offered was a particularly convenient form of entertainment (in the form of texting, verbal conversation and sometimes internet services) at the touch of a button, 'when I have nothing better to do'. Adolescent use of telephony services, for fun and enjoyment, was recognised several years ago by Williams et al. (1998). More recent studies 
Table 1: PCA explanatory factors - mobile gratifications

\begin{tabular}{|c|c|c|c|c|}
\hline Factor components & $\begin{array}{c}\text { Rotated } \\
d \text { score }\end{array}$ & Eigenvalue & $\begin{array}{c}\% \\
\text { explained }\end{array}$ & $\begin{array}{c}\text { Cronbach's } \\
\text { alpha }\end{array}$ \\
\hline Factor 1: Convenient entertainment & & 9.901 & 39.603 & 0.839 \\
\hline Because it entertains me & 0.810 & & & \\
\hline When I have nothing better to $\mathrm{do}^{*}$ & 0.616 & & & \\
\hline Because it relaxes me & 0.602 & & & \\
\hline Because it is so convenient & 0.550 & & & \\
\hline For the most up-to-date information and advice* & 0.552 & & & \\
\hline Because it amuses me & 0.551 & & & \\
\hline Because it's something I do with friends* & 0.464 & & & \\
\hline Factor 2: Social stimulation & & 1.883 & 7.531 & 0.807 \\
\hline Because it gives me a lift* & 0.633 & & & \\
\hline Because it is exciting ${ }^{*}$ & 0.626 & & & \\
\hline So I can be with other members of my family or friends & 0.606 & & & \\
\hline So I can learn how to do things* & 0.544 & & & \\
\hline To be like my friends & 0.523 & & & \\
\hline Because I just like to read them* & 0.422 & & & \\
\hline Factor 3: Experiential learning & & 1.483 & 5.933 & 0.782 \\
\hline Because it helps me form my moral/ethical values & 0.773 & & & \\
\hline It shows me what society is like nowadays & 0.688 & & & \\
\hline Because it helps me to learn things about myself and others & 0.615 & & & \\
\hline Factor 4: Escapism & & 1.116 & 4.462 & 0.714 \\
\hline So I can forget about school and other things & 0.753 & & & \\
\hline When there is no one else to talk to or be with & 0.706 & & & \\
\hline So I can get away from what I'm doing & 0.618 & & & \\
\hline Because I am curious as to what I am missing* & 0.396 & & & \\
\hline Factor 5: Purchase information and advice & & 1.037 & 4.150 & 0.286 \\
\hline Because it helps me decide what to buy & 0.795 & & & \\
\hline So I can talk with other people about what's on & 0.615 & & & \\
\hline
\end{tabular}

among Finnish teenagers have also highlighted the impulsive nature of phone-based entertainment (Wilska 2003).

The qualitative findings suggested that entertainment-based motivations are often socially interconnected, hence the loading on this factor of the statement 'because it's something I do with friends'; indeed, friends may well have been a key source of the 'entertainment', 'information', 
'advice' and 'amusement' associated with this factor. The very nature of texting, with its own particular form of abbreviated language and more risqué forms of communication (such as text flirting) was seen as entertainment in its own right, even enlivening time spent with parents:

A: 'I am texting people all the time, even when I am with my mum and dad ... it's like not that boring because even though there is nothing to do, you are always with your friends through your phone, you can have a laugh and that'

(female, 16, urban fee-paying school)

Constant access to socially derived entertainment helps explain why texting remains such a popular youth activity. There were also more specific, entertainment-based gratifications obtained through mobile phone use such as mobile gaming, exchanging pictures and TV programme texting.

\section{Factor 2: Social stimulation}

This second factor combines enlivening gratifications such as 'because it is exciting' and 'because it gives me a lift' with social gratifications such as 'so I can be with other members of my family or friends'. It suggests a linkage between the anticipation, and then subsequent gratification, of receiving a text or phone call from family and especially friends. This emphasises the importance of peer-based communication through new media (also evident in the popularity of websites such as MySpace.com). It also suggests that mobile use has important emotional dimensions overlooked by previous studies (Leung \& Wei 2000; Höflich \& Rössler 2001).

Discussing the rise of texting among British teenagers, a mobile marketing consultant observed that:

Texting is more than just a function, it is a vital part of their lives and the medium of choice; not only can it be used to convey the latest gossip and information, it is an ideal way for anonymous chatting, sharing secrets, and of course instigating romance (Tran 2003, p. 1).

In this study, the qualitative findings confirmed that mobile phones, and in particular texting, played an important role in maintaining social networks, to the extent that 'the link is more important than the thing' (Cova 1994): 
A: 'Well, I don't think I could live without it, it's a very important part of my life ... it is very useful because I don't know how I would organise things with my friends without my phone. I could use my house phone but that's not easy'

(female, 16, urban fee-paying school)

Texting, and to a lesser extent talking, on mobile phones, were seen as ways of keeping in touch, being kept in the social 'loop' and feeling part of the peer group - for example, by not missing out on nights out or the latest gossip. The fear of missing out and the need for reassurance regarding personal popularity were evident in several discussions. During one of the sessions, a 15-year-old boy received a text and proclaimed, 'Hey, I'm popular, I've just got a text message.' Although this was said with a degree of sarcasm, the fact that he was only too happy to announce his text to the group supports Taylor and Harper's (2001) argument concerning the performative value of mobile phones: they can be used to demonstrate involvement and status in social networks. However, it should be noted that this view of mobile phones was not universally endorsed. In one group, for example, participants distanced themselves from the mobile phone-obsessed culture of their peers, and one member of the group went on to complain about their intrusion into everyday conversations:

E: 'But I think mobile phones are anti-social ... because everyone that has got a phone, is just sitting there, speaking with the phone. I get annoyed with T., he always has his on. His is a video camera on his phone, which is quite sad, that people can't live without their phone'

(mixed group, 16, rural state school)

Sometimes texts from friends were responded to immediately, but at other times they were reflected upon and replied to later. It was this flexibility in communication that distinguished it from the location-bound internet or landline:

S: 'Well, texting is easier because you can do it anywhere because it is in your pocket and you can just contact someone or communicate with someone without having to call them. Really easy. Whereas I think I find e-mail a bit more of a nuisance. Especially because I don't have broadband'

(female, 15, urban fee-paying school) 
Such flexibility was beneficial in another important respect: young people's social networks are fluid and dynamic, creating a need for synchronisation that mobile phones are well equipped to meet (Tully 2002). They allowed young people to participate socially, wherever and whenever it suited them - at home, travelling, at school or out socialising. Gillard et al. (1998) referred to this constant adjustment of everyday activities using mobiles as 'micro-coordination'. As Berelowitz (2005, p. 21) puts it:

'Teenagers socialise in little packs, in public. The mobile allows the membership of the pack to be fluid, lets the pack stay on the move without getting isolated, and enables the different packs to locate (or avoid) one another.'

In one example, mobiles were used for a spontaneous get-together in a rural village centre to escape unwanted parents and consume alcohol away from the gaze of parents and local authorities. Texting doubled up as an early warning system should their illicit activities be discovered by unwanted parties.

The social connectedness of texting has an important spatial dimension. Two 14-year-old boys explained how texting can be understood as a form of virtual socialising:

Interviewer: 'Tell me why it is important to you then?'

M: 'Because I can just talk to my friends and text my friends'

A: 'It is a way of going out without going out'

M: 'Yes, it's a way of going out with your friends while you are in your bedroom' (boys, 14, urban fee-paying school)

Texting, then, fits within the 'media-rich' bedrooms of young people (Livingstone 2002), possibly encouraging them to retreat further into their own personal spaces when at home. In a similar manner to internet messenger boards, texting allowed young people to participate in social discourse while remaining at home. Such findings support contentions that new media use is creating new forms of socialisation, where physical presence is no longer a necessity (Agnelli et al. 2004).

In common with the internet, young people saw mobile phones as a more private form of communication. The blurring of public and private spaces (Dholokia \& Zwick 2003; Agnelli et al. 2004) was also evident, as participants talked about how texting allowed private exchanges to take 
place in public places, sometimes in close proximity to others:

A: 'You can say what you want without having to say it, it's more private. If you want to say it to someone and maybe they are in a public place, they can get a beep and they can read it out without anyone else hearing the conversation'

(female, 15, suburban state school)

Since schoolmates, teachers, or parents could be present but cut out from such exchanges, mobile phones served as tools of social exclusion as well as social connectedness.

\section{Factor 3: Experiential learning}

The third dimension has a close resemblance to the 'experiential learning' applicable to the internet (Grant 2005). Its importance for understanding mobile phone use is less significant however. The dimension does suggest that young people use mobile phones for classic media reasons of 'learning about themselves and others', although the gratification statements do not specify the nature of these information-based experiences. At the very least, however, it seems that young people are willing to consider their phones as tools for learning more about themselves and others. It would require considerable advances in technology and services before mobiles could approach the internet's capacity to deliver such gratifications. It should also be noted that this factor was rarely talked about in the qualitative discussions, suggesting that young people do not have rich experiences concerning mobile phone use for learning purposes. This highlights the distance between standardised uses and gratifications approaches and the lived-in everyday experiences of media consumption, and underlines the benefits of multiple methods of enquiry.

\section{Factor 4: Escapism}

Immediate, personal access to mobile phones makes them an ideal conduit for escapism - drifting away mentally from particular activities or organisations, or simply from everyday boredom, regardless of location or company. The emphasis here, however, appears more on combating social loneliness ('when there is no one to talk to or be with') rather than activity driven ('when there is nothing better to do'). As one female participant put it, 'I just keep it on just in case somebody wants to speak to me.' 
Escapism was also found as a form of avoidance behaviour (Berelowitz 2005); texting rather than speaking allowed participants to remain at arm's length, choosing a convenient time and place to communicate:

F: 'Aye, they're good for wasting time ... and if you don't want to actually talk to anyone, you can just text them when it suits'

(female, 14, suburban state school)

The qualitative findings confirmed that playing games and texting on phones were perceived as ideal ways of 'filling in' or 'wasting' time. When asked what was the ideal time to text, one female suggested it was simply when she could think of 'nothing else to do'. The closeness and convenience of the mobile phone made it uniquely suitable for this immediate gratification - it was always on hand to combat boredom.

\section{Factor 5: Purchase information and advice}

Finally, and in common with the internet (Grant 2005), there appeared to be only weak motivations for using mobile phones for commercial engagement, or 'to help decide what to buy'. The factor can be considered unreliable given its low Cronbach's alpha score, offering little indication of a strong relationship between mobile phones and the desire to engage with commercial consumption. Given so little evidence of purchase-related motivations, the qualitative sessions were used to explore young people's commercial contact through mobile devices.

A few participants agreed that mobile phones might be an acceptable media platform for branded communication. Acknowledging that they carried their mobiles with them at all times, they grudgingly accepted that some forms of commercial text-based communication might benefit recipients as well as senders:

Interviewer: 'How would you feel if a company sent you information through your mobile phone?'

L: 'I think that could be quite handy, if it was for latest concert dates and that kind of thing, or new ringtones'

L: 'Yeah, like new concert dates, but if it was through the internet, well, I'm not on it every day. Like last week, we wanted to go to the SECG [a major concert venue] in Glasgow, phoned them up but they were sold out. A text giving advance warning would have been great'

(females, 14, rural state school) 
Interviewer: 'Say there was a Robbie Williams concert coming up, and they texted you to say that tickets were going on sale soon, would you welcome that kind of marketing?'

A: 'Yeah that would be welcome because if the concert tickets were going on sale in an hour, you would have your mobile in your pocket and respond immediately'

(females, 14, suburban state school)

The examples above highlighted the importance of 'communication relevance' as well as 'communication timeliness'. Communication was acceptable if it involved content that they might not have been able to access otherwise. Their description of getting hold of concert tickets suggested that such communication might give them a sense of privilege, accessing valuable information that their peers had not been able to.

There were some examples of participants using mobile phones to initiate or respond to branded communications. Beyond programme texting, young people discussed texting back for branded promotions (such as for the convenience food brand Pot Noodle), and texting for downloadable mobile ringtones or games. They also mentioned receiving texts from well-known high-street brands (such as McDonald's) and youth-targeted magazines (such as Sugar), but claimed not to be tempted to respond. Such examples frequently relied on an entertainment-based promotional mechanism to encourage interaction. There was also one example of a received text offering educational advice, from a government youth organisation known as YoungScot. In this case, a 14-year-old boy recounted receiving information on selected social issues including combating drug taking and smoking. It should be stressed that this was an isolated example, welcomed by the individual but not embraced by any of his peers.

There were very few examples of young people choosing to respond to companies through their mobile phones. Such examples were generally driven by short-term incentives rather than the prospect of ongoing relationships as desired by practitioners. In this study, therefore, there was little to suggest that young people welcomed the prospect of mobile communications unless relatively infrequent and highly relevant. Furthermore, as discussed below, participants expressed considerable concern about commercial intrusion through mobile phones. 


\section{Commercial intrusion through mobile phones}

Young people voiced concerns about the growing 'threat' of commercial intrusion through their mobile phones. Unlike the internet, mobile phones (especially texting) elicited almost universal enthusiasm among young people. As discussed above, mobile phones were used primarily for social and entertainment rather than informational and purchasing reasons. It was therefore not surprising that attempts by commercial organisations to send text-based adverts were widely disliked. Of particular concern to practitioners should be the fact that this covered both unsolicited texts and excessive use of permission-based texts.

One of the most obvious forms of annoyance stemmed from the limited capacity of mobile phone memories. Young people resented an inbox 'clogged up' with advertisements:

S: 'It would be really annoying. Because my phone only holds about ten text messages and then if you are getting text messages from other things taking up your whole box, you might get excited because you think that your friends have texted you, and then you discover it is just another boring advert'

(female, 15, rural state school)

As this quote highlights, annoyance was not only due to the functional limitations of the technology. Receiving text messages from friends was clearly an important activity and any blocking of personal communication was deeply resented. Receiving what was thought to be a text from a friend clearly raised expectations of something stimulating. On discovering the true identity of the sender, S clearly felt let down. Such actions could have harmful effects on the reputation of the sender, creating a strong adverse reaction.

There were also indications that repeated attempts at text-based communication, even if initially permission-based, could be frustrating. Such practices were arguably more difficult to avoid, accentuating feelings of intrusion since text messages are read sequentially:

L: 'There's this company that offers ringtones, logo screen savers. They have got a website and you can either text them and it takes something like $£ 3.00$ off your balance or you can phone the 0800 number ... but recently they keep sending me texts and I can't get rid of them'

(female, 16, suburban state school) 
J: 'It's a magazine, Sugar, that texts me. I texted them for some reason or another and they never stop texting me. I tell them to stop and it ends up costing me an extra £1.50’

(female, 15, suburban state school)

These text-based practices were viewed as tantamount to commercial harassment, deepening feelings of mistrust and general annoyance, especially since attempts to stop such practices were considered time-consuming and expensive. These findings extend Monk et al.'s (2004) findings on mobile annoyance with particular reference to commercial contact.

\section{Discussion and conclusions}

These findings indicate the centrality of mobile phones in the lifestyles of young people; they are woven into the fabric of their daily lives, in and beyond the home. Clearly there is much scope for further research in this area, not least in tracking the evolution of young people's relationships with MMC over time. Other consumer groups may have very different experiences with and expectations of mobile phones, however, and these also merit research attention.

The dominant motivation for young people's mobile phone use identified in this study was convenient entertainment. This suggests that mobile phones offer an alternative to traditional forms of mediated entertainment such as television, with the immediacy of access to content and gaming providing instant gratification. However, such entertainmentbased motivations were not enjoyed in a social vacuum. The social element of the first factor ('something to do with friends') and the characteristics of the second most powerful factor, 'social stimulation', remind us that mobile phones play a central role in peer-related communication, providing a sense of connection through the exchange of voice, text, rich media and gaming. This suggests the potential for mobile-orientated subscription-based services as suggested by Mort and Drennan (2005). The picture is less optimistic, however, for marketing communications practitioners. The findings indicate little motivation among young people to use mobile phones to obtain commercial information or advice; instead, these devices were valued for their non-commercial, personal and socially orientated uses. 
This paper also indicates the value of combining traditional uses and gratifications measures with a more qualitative and contextualised approach. In this case, for example, the factor analysis pointed towards 'convenient entertainment' as the primary motivator, whereas the qualitative research highlighted the ways in which social connectedness was intertwined with, and fundamental to, the entertainment to be derived from mobile phones.

Consumer experiences of MMC to date remain limited and more research is needed to explore how mobile marketing communication is received and acted upon as it continues to evolve. In this study, the qualitative findings indicated strong negative feelings among young people for marketing communications targeted through their phone, even if permission had been granted at some stage. There were examples of valued communication provided the message was timely and very well targeted, which occasionally resulted in an exchange or interaction with the sender. However, such experiences were not the norm. This could perhaps be explained away by the infancy of mobile marketing communication, with technological and creative limitations inhibiting positive initial responses, as was the case with other 'new' media such as the internet (Yuan et al. 1998).

In this case, adolescents' resistance to commercial practices ranged from low-level feelings of annoyance to more emotive concerns about trust and personal intrusion. More fundamentally, it seemed that they were not positively disposed towards - and did not even consider - mobile phones as a commercial media channel. The fact that they referred to 'their' mobile phone, but not 'their' internet or TV channel indicates the different levels of personal investment at stake. The mobile may well be a 'brand in the hand' from a practitioner perspective - but for the young people this device represented a friend in the hand, and any commercial communication must take account of this. This does not mean that brand should engage in an undignified scramble to befriend youth audiences; such approaches are likely to be met with scorn. Rather, mobile marketing communicators should know their place, and focus on how they can offer content capable of facilitating real friendships rather than simulating (or interrupting) them. Willis (1990) talked about ads as 'tokens of social exchange' among young people, and marketers who find ways of offering such tokens through mobile devices seem more likely to succeed with this 
audience. In other words, they have to bring something to the party, rather than simply gatecrashing it.

\section{References}

Agnelli, D., Dario, B. \& Tal, D. (2004) Fashion victims: an unconventional research approach in the field of mobile communications, at http://people.interaction-ivrea.it/d.agnelli/on/fv/resources/ismid04_fv_v01.pdf

Ahonen, T. (2006) A mobile phone for every living person in western Europe: penetration hits $100 \%$, at http://communities-dominate.blogs.com/brands/2006/03/ phone_for_every.html

Arnett, J.J. (2000) Emerging adulthood: a theory of development from the late teens to the late twenties. American Psychologist, 55(5), pp. 469-481.

Berelowitz, M. (2005) Endpiece: children, young people and mobile phones, in Haste, H. (ed.) Joined-up Texting, Nestlé Social Research Programme, p. 21, at http://www.mori.com/polls/2004/pdf/nestlesrp3.pdf.

Bigelow, L. (2002) A brand in your hand. Admap, March, pp. 47-50.

BMRB (2001) Target Group Index. London: British Market Research Bureau.

Buckingham, D. (2000) After the Death of Childhood: Growing Up in the Age of Electronic Media. Malden, MA: Polity Press.

Bughin, J.R. (2004) Using mobile phones to boost TV ratings, McKinsey Quarterly, 24 May, at http://www.mckinseyquarterly.com.

Cova, B. (1994) Community and consumption: towards a definition of the 'linking value' of product or services. European Journal of Marketing, 31(3/4), pp. 297-316.

Dholakia, N. \& Zwick, D. (2003) Mobile technologies and boundaryless spaces: slavish lifestyles, seductive meanderings, or creative empowerment?, at http://ritim.cba.uri.edu/wp2003/pdf_format/HOIT-Mobility-Technology-Boundarypaper-v06.pdf.

Eighmey, J. \& McCord, L. (1998) Adding value in the information age: uses and gratifications of sites on the World Wide Web. Journal of Business Research, 41, pp. 187-194.

Gillard, P., Wale, K. \& Bow, A. (1998) The friendly phone, in Howard, S. (ed.) Wired Up: Young People and the Electronic Media. London: UCL Press, pp. 135-152.

Grant, I.C. (2005) Young people's relationships with online marketing practices: an intrusion too far? Journal of Marketing Management, 21(5), pp. 607-623.

Hair Jr, J.F., Anderson, R.E., Tatham, R.L. \& Black, W.C. (1998) Multivariate Data Analysis, 5th edn. Upper Saddle River, NJ: Prentice Hall.

Haste, H. (2005) Joined up texting: mobile phones and young people. Young Consumers, 6(3), at http://www.warc.com.

Höflich, J.R. \& Rössler, P. (2001) Mobile schriftliche kommunikation oder: e-mail für das handy. Medien \&o Kommunikationswissenschaft, 49, pp. 437-461.

Jones, A. (2002) Wireless marketing: the linking value of text messaging. Journal of Advertising $\&$ Marketing to Children, January-March, pp. 39-44.

Katz, E., Gurevitch, M. \& Hass, H. (1973) On the use of the mass media for important things. American Sociological Review, 38, pp. 164-181. 
Katz, J. (1996) The rights of kids in the digital age. Wired, 4th July, p. 123.

Leung, L. \& Wei, R. (2000) More than just talk on the move: uses and gratifications of the cellular phone. Journalism and Mass Communication Quarterly, 77(2), pp. 308-320.

Lin, C.A. (1996) Looking back: the contribution of Blumler and Katz's uses and mass communication to communication research. Journal of Broadcasting Ë Electronic Media, 40, pp. 574-581.

Ling, R. (2004) 'It is “in”. It doesn't matter if you need it or not, just that you have it': fashion and the domestication of the mobile telephone among teens in Norway, in Ling, R. (ed.) The Mobile Connection: The Cell Phone's Impact on Society. San Francisco: Morgan Kaufmann.

Ling, R. \& Helmersen, P. (2000) 'It must be necessary, it has to cover a need': the adoption of mobile telephony among pre-adolescents and adolescents. Paper presented at Conference on the Social Consequences of Mobile Telephony, 16 June, Oslo.

Livingstone, S. (2002) Young People, New Media: Childhood and the Changing Media Environment. London/Thousand Oaks: Sage Publications.

Madell, D. \& Muncer, S. (2004) Back from the beach but hanging on the telephone? English adolescents' attitudes and experiences of mobile phones and the internet. CyberPsychology \& Behavior, 7(3), pp. 359-367.

Mante-Meyer, E. \& Haddon, L. (eds) (2001) Checking it Out with the People - ICT Markets and Users in Europe. Eurescom Project Report, Eurescom Project P-903. Germany: Eurescom.

McLoone, P. (1997) Carstairs Scores for Scottish Postcode Sectors from the 1991 Census. Glasgow: Public Health Research Unit, University of Glasgow.

Mitchell, L. (1997) Pressure groups: young people's accounts of peer pressure to smoke. Social Sciences in Health, 3, pp. 3-16.

Monk, A., Carroll, J., Parker, S. \& Blythe, M. (2004) Why are mobile phones annoying? Behaviour and Information Technology, 23(1), pp. 33-41.

Mort, G.S. \& Drennan, J. (2004) Marketing m-services: establishing a usage benefit typology relating to mobile user characteristics. Database Marketing \& Customer Strategy Management, 21(4), pp. 327-341.

NCH (2005) Putting $U$ in the Picture: Mobile Bullying Survey 2005, at http://www.nch.org.uk/uploads/documents/Mobile_bullying_\%20report.pdf.

O’Donohoe, S. (1994) Advertising uses and gratifications. European Journal of Marketing, 28(8/9), pp. 52-75.

Oksman, V. \& Raitiainen, T. (2001) Perhaps it is a body part. How the mobile phone became an organic part of everyday lives of children and teenagers. Paper presented at Nodiska konferensen för medie-ock kommunikationfiorskning, Island, 11-13 August.

Oksman, V. \& Turtiainen, J. (2004) Mobile communication as a social stage: meanings of mobile communication in everyday life among teenagers in Finland. New Media छ Society, 6(3), at http://www.new-media-and-society.com.

Pedersen, P.E. \& Ling, R. (2002) Modifying adoption research for mobile internet service adoption: cross-disciplinary interactions. Proceedings of the 36th Hawaii International Conference on Systems Sciences. IEEE Computer Society. 
Pedrozo, S. \& Wilska, T.-A. (2004) Mobile phones and young people's consumer identities: a comparison study between Finland and Brazil. Proceedings of Digital Generation: Children, Youth and Media. London: Institute of Education, University of London, 26-29 July.

Ritson, M. \& Elliott, R. (1999) The social uses of advertising: an ethnographic study of adolescent advertising audiences. Journal of Consumer Research, 26(3), pp. 260-277.

Robson, C. (1993) Real World Research: A Resource for Social Scientists and PractitionerResearchers. Oxford: Blackwell Publishers.

Rohm, A.J. \& Sultan, F. (2005) Brand in the hand: an exploratory study of mobile marketing communications. Proceedings of EURAM 2005, April, Munich.

Ruggiero, T.E. (2000) Uses and gratifications theory in the 21 st century. Mass Communication \& Society, 3(1), pp. 3-37.

Skog, B. (2002) Mobiles and the Norwegian teen: identity, gender and class, in Katz, J.E. \& Aakhus, M. (eds) Perpetual Contact. New York: Cambridge University Press.

Steinbock, D. (2005) The Mobile Revolution. London: Kogan Page Ltd.

Taylor, A.S. \& Harper, R. (2001) Talking activity: young people and mobile phones. Paper presented at CHI 2001 Workshop: Mobile Communications: Understanding Users, Adoption and Design.

Thompson, C.J., Locander, W.B. \& Pollio, H.R. (1989) Putting consumer experience back into consumer research: the philosophy and method of existential phenomenology. Journal of Consumer Research, 16, pp. 133-146.

Tran, T. (2003) How to tap into the teen text market. Journal of Advertising and Marketing to Children, 4, at www.warc.com.

Tully, C.J. (2002) Youth in motion: communicative and mobile, a commentary from the perspective of youth sociology. Youth, 10(2), pp. 19-43.

Vanderbeeken, M. (2004) Interview with Davide Agnelli, at http://www.interaction-ivrea.it/en/people/d.agnelli/index.asp.

Williams, F., Rice, R.E. \& Rogers, E.M. (1998) Research Methods and the Nerw Media. London: The Free Press.

Willis, P. (1990) Common Culture. Milton Keynes: Open University Press.

Wilska, T.-A. (2003) Mobile phone use as part of young people's consumption. Journal of Consumer Policy, 26, pp. 441-463.

Yuan, Y., Caulkins, J. \& Roehrig, S. (1998) The relationship between advertising and content provision on the internet. European Journal of Marketing, 32(7/8), pp. 677-687.

\section{About the authors}

Ian Grant is Senior Lecturer in Marketing at the University of Strathclyde. He has recently been researching the differences in how young consumers use traditional and new forms of media, and the implications for marketing 
practice. This research spans his interests in digital communications, lifestyle and media consumption. As a former advertising planner, Ian has also published on advertising planning, strategy and consumption. Recent publications include papers appearing in the Journal of Marketing Management, Journal of Marketing Communications, Qualitative Market Research: An International Journal and Advances in Consumer Research.

Stephanie O'Donohoe is Senior Lecturer in Marketing at The University of Edinburgh. Her research interests include the production and consumption of advertising, marketing and advertising to children, and consumption experiences during bereavement and in the transition to motherhood. Her work has been published in journals such as the International Journal of Advertising, European Journal of Marketing, Journal of Marketing Management and Human Relations.

Address correspondence to: Ian Grant, University of Strathclyde, Department of Marketing, Stenhouse Building, 173 Cathedral Street, Glasgow G4 0RQ

Email: ian.grant@strath.ac.uk 
Copyright of International Journal of Advertising is the property of WARC World Advertising Research Center and its content may not be copied or emailed to multiple sites or posted to a listserv without the copyright holder's express written permission. However, users may print, download, or email articles for individual use. 